\title{
Glioblastoma multiforme with very rapid growth and long-term survival in children: report of two cases and review of the literature
}

\author{
Mahmoud Reza Khalatbari • Mehrdokht Hamidi • \\ Yashar Moharamzad
}

Received: 20 October 2011 / Accepted: 21 October 2011 /Published online: 18 November 2011

(C) Springer-Verlag 2011

\section{Dear Editor:}

We read the "Letter to Editor" by Borkar et al. regarding our article [1]. We found this letter interesting and informative. It provides useful data about the authors' experience regarding management of pediatric glioblastoma multiforme (GBM) with a considerable sample size of 70 patients at their medical center.

The strength of this report is performing genetic analyses in a group of pediatric patients and notable finding of uncommon epidermal growth factor receptor amplification and phosphate and tensin homolog gene deletion as opposed to p53 expression in $63 \%$ of cases and loss of p16 (68\%) and p27 (54\%) immunoexpression which are significant alterations in pediatric GBM compared to their adult counterpart [2].

Unfortunately we do not currently have access to detailed genetic or molecular study techniques at our center. Therefore, we are not able to perform more studies about molecular genetics of described patients. All we know are those mentioned in the article: the first patient's tumor was negative for p53 and had a Ki-67 index of 30\%. The second patient's left hemisphere tumor showed a Ki-67 index of 24\%, and the tumor nuclei were negative for $\mathrm{p} 53$. The right hemisphere tumor had a $\mathrm{Ki}-67$ index of $11 \%$, and $10 \%$ of the nuclei were positive for $\mathrm{p} 53$. Hence, we cannot accept or refuse available literature about relationship between genetic factors and longterm survival in pediatric GBM.

Mahmoud Reza Khalatbari

Mehrdokht Hamidi

Yashar Moharamzad

\section{References}

1. Khalatbari MR, Hamidi M, Moharamzad Y (2011) Glioblastoma multiforme with very rapid growth and long-term survival in children: report of two cases and review of the literature. Childs Nerv Syst 27:1347-1352

2. Suri V, Das P, Pathak P, Jain A, Sharma MC, Borkar SA et al (2009) Pediatric glioblastomas: a histopathological and molecular genetic study. Neuro Oncol 11:274-280

M. R. Khalatbari • Y. Moharamzad ( $\square)$

Neurosurgery, Arad Hospital,

Somayeh Street,

Tehran, Iran

e-mail: yasharpop@hotmail.com

\section{Hamidi}

Pathology, Arad Hospital,

Somayeh Street,

Tehran, Iran 